\title{
ENSAIO DE DESBASTE DE RAMOS INFERIORES DO CAFEEIRO II
}

\author{
J. E. Teixeira Mendes \\ Engenheiro agrônomo, Seç̧ão de Café, Instituto Agronômico de Campinas
}

\section{1 - INTRODUÇÃO}

Em trabalho anterior (1) já demos conta dos resultados obtidos neste ensaio no período que decorreu de 1935 a 1944. Os dados obtidos demonstraram que não houve vantagem em se proceder à eliminação dos ramos inferiores do cafeeiro, que constituem o que geralmente se chama de "saia". Os resultados demonstraram superioridade para a série em que não houve interferência alguma e em que, portanto, os cafeeiros se desenvolveram livremente.

O plano do ensaio é o mesmo já relatado. Possui apenas dois tratamentos : $a$ ) série desbastada ; $b$ ) série não desbastada. Cada série é composta de 5 repetições, tendo cada repetição 25 cafeeiros (covas com quatro plantas em cada uma). A variedade empregada foi o Café Nacional, isto é, Coffea arabica L. var. typica Cramer.

\section{2 - ADUBAÇÕES E TRATOS CLLTURAIS}

As adubações têm sido feitas anualmente para que as plantas se mantenham em boas condições. A relação que se segue dá a indicação das adubações empregadas por cafeeiro, ano por ano, de 1945 a 1950.

Ano 1945

Quantidade em gramas

Torta de algodão

1.000

Fosfato de potássio 200

Ano 1946

Estêrco

Torta de algodão......

Fosfato de potássio

Ano 1947

Estêrco

Torta de algodão..

Fosfato de potássio

ANo 1948

Palha de café

Farinha de ossos

Cloreto de potássio

Salitre do Chile 
Ano 1949

Quantidade em gramas

Serranafosfato

200

Cloreto de potássio

100

Salitre do Chile

100

ANo 1950

Estêrco

5.000

Torta de algodão

800

Superfosfato

200

Cloreto de potássio

100

Tratos culturais - Os tratos culturais têm sido idênticos para as duas séries de plantas, exceto no que diz respeito ao desbaste dos ramos inferiores, que foi praticado apenas na série desbastada. As capinas foram feitas sempre ao mesmo tempo e o sistema de defesa contra a erosão é idêntico.

Prática do desbaste dos ramos inferiores - A série desbastada é mantida sem ramos primários e inferiores até uma altura de pouco mais ou menos $50 \mathrm{~cm}$ do solo. A desbrota foi feita em ambas as séries de modo a serèm mantidos apenas os ramos necessários para a recomposição das plantas.

\section{3 - COLHEITA E RESULTADOS OBTIDOS ATE 1944}

As colheitas têm sido realizadas em dois ou três repasses anuais, para se colhêr, tanto quanto possivel, os frutos maduros. As produções médias obtidas no período de 1935 a 1944, relatadas em trabalho anterior (1), foram as seguintes :

\begin{tabular}{|c|c|c|c|}
\hline SÉRIE & Café maduro & Café em côco & $\begin{array}{c}\text { Café beneficiado } \\
\mathrm{kg}\end{array}$ \\
\hline $\begin{array}{l}\text { Desbastada } \\
\text { Não desbastada }\end{array}$ & $\begin{array}{r}90,4 \\
105,2\end{array}$ & $\begin{array}{l}40,5 \\
47,2\end{array}$ & $\begin{array}{l}20,2 \\
23,7\end{array}$ \\
\hline
\end{tabular}

Verifica-se, pois, que não houve vantagem em se fazer a poda dos ramos inferiores, pois que, em dez safras, a média da produção foi maior na série não desbastada.

\section{4 - RESULTADOS OBTIDOS DE 1945 a 1950}

No quadro 1 vêm as produções em café cereja, café em côco e café beneficiado, obtidas nas duas séries nos anos que vão de 1945 a 1950.

Verifica-se, pelo exame do quadro 1, que em 6 anos, no período que decorreu de 1945 a 1950, a série não desbastada produziu mais do que a desbastada. Tomando-se o café em côco para base de comparação, vemos que apenas em dois anos, isto é, em 1947 e 1949, os cafeeiros desbastados produziram mais do que os da série não podada, mas, assim mesmo, as diferenças foram muito pequenas. A produção média, em café em côco no período examinado, na série não desbastada, foi de $13,1 \%$ maior do que na desbastada. 
Qundro 1.--Produções médias de café, em diferentes formas, no período 1945-1950

\begin{tabular}{|c|c|c|c|c|c|c|}
\hline \multirow[b]{2}{*}{$A n \circ s$} & \multicolumn{3}{|c|}{ Série desbastada } & \multicolumn{3}{|c|}{ Série não desbastada } \\
\hline & $\begin{array}{c}\text { Café } \\
\text { cereja }\end{array}$ & $\begin{array}{c}\text { Café em } \\
\text { côco }\end{array}$ & $\begin{array}{l}\text { Café bene- } \\
\text { ficiado }\end{array}$ & $\begin{array}{c}\text { Café } \\
\text { cereja }\end{array}$ & $\begin{array}{c}\text { Café em } \\
\text { côco }\end{array}$ & $\begin{array}{c}\text { Café bene- } \\
\text { ficiado }\end{array}$ \\
\hline & $k g$ & $k g$ & $\mathrm{~kg}$ & kig & $k \boldsymbol{g}$ & $k g$ \\
\hline $\begin{array}{l}1945 \\
1946 \\
1948\end{array}$ & $\begin{array}{r}67,08 \\
99,02 \\
58,78 \\
151,60 \\
45,12 \\
162,26\end{array}$ & $\begin{array}{l}32,50 \\
58,12 \\
30,82 \\
71,60 \\
23,44 \\
69,60\end{array}$ & $\begin{array}{l}15,04 \\
27,86 \\
15,94 \\
36,84 \\
11,33 \\
36,03\end{array}$ & $\begin{array}{r}99,88 \\
124,42 \\
59,70 \\
169,20 \\
44,74 \\
178,86\end{array}$ & $\begin{array}{l}45,61 \\
69,62 \\
30,32 \\
79,10 \\
22,88 \\
76,00\end{array}$ & $\begin{array}{l}21,14 \\
33,85 \\
16,05 \\
40,94 \\
11,21 \\
39,71\end{array}$ \\
\hline Média & 97,31 & 47,68 & 23,96 & 112,80 & 53,92 & 27,15 \\
\hline
\end{tabular}

\section{5 - RESULTADOS OBTIDOS NO PERÍODO TODO : 1935-1950}

O quadro 2 dá a produção obtida em todo o período em que o ensaio vem sendo examinado.

Quadro 2.--Produções médias de café em diferentes formas, no período de 1935-1950

\begin{tabular}{|c|c|c|c|c|c|c|}
\hline \multirow{2}{*}{$A \| \mathrm{os}$} & \multicolumn{3}{|c|}{ Série desbastada } & \multicolumn{3}{|c|}{ Série não desbastada } \\
\hline & $\begin{array}{c}\text { Café } \\
\text { cereja }\end{array}$ & $\begin{array}{c}\text { Café em } \\
\text { cốco }\end{array}$ & $\begin{array}{l}\text { Café bene- } \\
\text { ficiado }\end{array}$ & $\begin{array}{c}\text { Café } \\
\text { cereja }\end{array}$ & $\begin{array}{l}\text { Café em } \\
\text { côco }\end{array}$ & $\begin{array}{l}\text { Café bene- } \\
\text { ficiado }\end{array}$ \\
\hline & $k g$ & ko & $k g$ & $k g$ & $k g$ & $k g$ \\
\hline 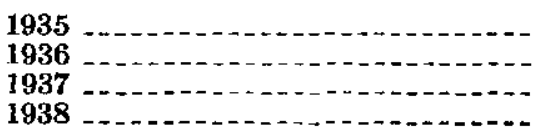 & $\begin{array}{r}27,70 \\
72,20 \\
57,99 \\
208,33\end{array}$ & $\begin{array}{l}11,70 \\
30,77 \\
24,77 \\
92,76\end{array}$ & $\begin{array}{r}5,59 \\
14,41 \\
11,81 \\
49,96\end{array}$ & $\begin{array}{r}47,63 \\
76,86 \\
64,37 \\
250,86\end{array}$ & $\begin{array}{r}22,32 \\
32,61 \\
28,80 \\
108,49\end{array}$ & $\begin{array}{l}10,25 \\
15,33 \\
13,75 \\
57,96\end{array}$ \\
\hline $\begin{array}{l}1939 \\
1940 \\
1941 \\
1942\end{array}$ & $\begin{array}{r}13,67 \\
188,98 \\
8,56 \\
101,06\end{array}$ & $\begin{array}{r}6,64 \\
87,36 \\
3,78 \\
47,84\end{array}$ & $\begin{array}{r}3,25 \\
44,16 \\
1,67 \\
24,08\end{array}$ & $\begin{array}{r}21,79 \\
216,60 \\
12,64 \\
115,10\end{array}$ & $\begin{array}{r}10,27 \\
99,34 \\
5,36 \\
55,92\end{array}$ & $\begin{array}{r}5,14 \\
50,14 \\
2,44 \\
28,67\end{array}$ \\
\hline $1943-1944,-1945$ & $\begin{array}{r}86,80 \\
138,86 \\
67,08 \\
99,02\end{array}$ & $\begin{array}{l}39,02 \\
60,16 \\
32,50 \\
58,12\end{array}$ & $\begin{array}{l}19,57 \\
27,94 \\
15,04 \\
27,86\end{array}$ & $\begin{array}{r}112,38 \\
134,00 \\
99,88 \\
124,42\end{array}$ & $\begin{array}{l}50,84 \\
58,48 \\
45,61 \\
69,62\end{array}$ & $\begin{array}{l}25,68 \\
27,31 \\
21,14 \\
33,85\end{array}$ \\
\hline $\begin{array}{l}1947 \\
1948 \\
1949 \\
1950\end{array}$ & $\begin{array}{r}58,78 \\
151,60 \\
45,12 \\
162,26\end{array}$ & $\begin{array}{l}30,82 \\
71,60 \\
23,44 \\
69,60\end{array}$ & $\begin{array}{l}15,94 \\
36,84 \\
11,33 \\
36,03\end{array}$ & $\begin{array}{r}59,70 \\
169,20 \\
44,74 \\
178,86\end{array}$ & $\begin{array}{l}30,32 \\
79,10 \\
22,88 \\
76,00\end{array}$ & $\begin{array}{l}16,05 \\
40,94 \\
11,21 \\
39,71\end{array}$ \\
\hline Média .. & 93,00 & 43,18 & 21,62 & 108,07 & 49,75 & 24,97 \\
\hline
\end{tabular}

Tomando-se o café em côco como têrmo de comparação, verifica-se que a produção foi maior em todo o período para a série não desbastada. Houve uma vantagem de $15,2 \%$ para esta, em relação à que sofreu a poda dos ramos inferiores.

$\mathrm{E}$ interessante notar que a diferença entre as duas séries diminuiu nos últimos anos. Como vimos no período 1945-50, a série não desbastada superou a desbastada em 13,1\%.

Se calcularmos a produção por mil cafeeiros como se estimam as safras de café em São Paulo, vamos obter os dados do quadro 3. 
Qualsro 3.--Produção de café por 1.000 plantas no período 1935-50

\begin{tabular}{|c|c|c|c|c|}
\hline \multirow{2}{*}{ A n o s } & \multicolumn{2}{|c|}{ Série desbastada } & \multicolumn{2}{|c|}{ Série não desbastada } \\
\hline & Quilograma & Arrobr & Quilograma & Arroba \\
\hline $\begin{array}{l}1935 \\
1936 \\
1937 \\
1938\end{array}$ & $\begin{array}{r}223,6 \\
576,4 \\
472,4 \\
1.998,4\end{array}$ & $\begin{array}{r}14,9 \\
38,4 \\
31,5 \\
133,2\end{array}$ & $\begin{array}{r}410,0 \\
613,2 \\
550,0 \\
2.318,4\end{array}$ & $\begin{array}{r}27,3 \\
40,9 \\
36,7 \\
154,5\end{array}$ \\
\hline $\begin{array}{l}1939 \\
19401 \\
1942\end{array}$ & $\begin{array}{r}130,0 \\
1.766,4 \\
66,8 \\
963,2\end{array}$ & $\begin{array}{r}8,7 \\
117,8 \\
4,5 \\
64,2\end{array}$ & $\begin{array}{r}205,6 \\
2.005,6 \\
97,6 \\
1.146,8\end{array}$ & $\begin{array}{r}13,7 \\
133,7 \\
6,5 \\
\mathbf{7 6 , 5}\end{array}$ \\
\hline $\begin{array}{l}1943 \\
1944 \\
1945 \\
1946\end{array}$ & $\begin{array}{r}780,4 \\
1.117,6 \\
601,6 \\
1.114,4\end{array}$ & $\begin{array}{l}52,0 \\
74,5 \\
40,1 \\
74,3\end{array}$ & $\begin{array}{r}1.027,2 \\
1.092,4 \\
845,6 \\
1.354,0\end{array}$ & $\begin{array}{l}68,5 \\
72,8 \\
56,4 \\
90,3\end{array}$ \\
\hline $\begin{array}{l}1947 \\
1948 \\
1949\end{array}$ & $\begin{array}{r}637,6 \\
1.473,6 \\
4.53,2 \\
1.441,2\end{array}$ & $\begin{array}{l}42,5 \\
98,2 \\
30,2 \\
96,1\end{array}$ & $\begin{array}{r}642.0 \\
1.637,6 \\
448,4 \\
1.588,4\end{array}$ & $\begin{array}{r}42,8 \\
109,2 \\
29,9 \\
105,9\end{array}$ \\
\hline Média -: & 863,6 & 57,6 & 998,9 & 66,6 \\
\hline
\end{tabular}

Até o presente, após 16 colheitas, não houve vantagem em sc fazer o desbaste dos ramos inferiores, neste ensaio.

\section{6 - MATUTRAÇÃO DO CAFE}

Não foi possível neste último período do ensajo, fazer o número suficiente de colheitas para só retirar das plantas café maduro. Foram feitas sòmente duas colheitas anualmente, sendo que a primeira, no geral, se realizou tarde, o que não permitiu se tivesse uma idéia melhor de como se processou a maturação dos frutos nas duas séries. O quadro 4 dá a quantidade de café colhido em cada vez e a respectiva percentagem.

Como se vê nos dados referentes ao período 1945-50, apenas em um ano, no de 1949, a série não desbastada apresentou maior quantidade de café na primeira colheita. No período anterior, apenas no ano de 1936 ocorreu fato idêntico. Examinando-se o aumento ou diminuição da percentagem de maturação entre ambas as séries, tomando-se por base a série desbastada, obtêm-se os dados s?g Iintes:

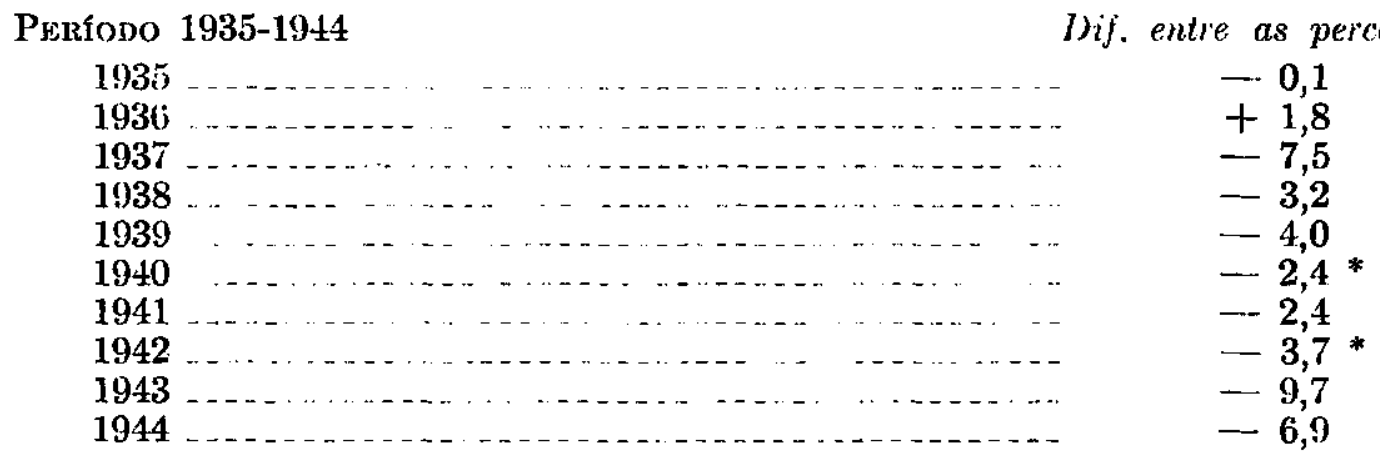

(*) Os numeros assinalados com asteriscos se referen as $1 . .^{\mathrm{a}}$ e $2 .^{\mathrm{a}}$ colheitas, por ter sido a prineira collseita muito pequena. 
Período 1945-1950

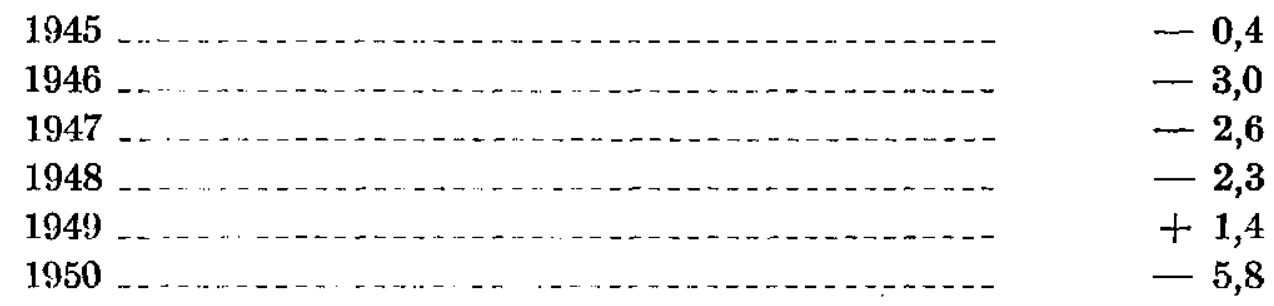

Verifica-se que em 16 safras, apenas em duas a série não desbastada apresentou pequena percentagem a mais de frutos maduros do que a desbastada.

Há, portanto, uma pequena vantagem para as plantas podadas com relação ao amadurecimento dos frutos. E provável que a maior quantidade de frutos verdes que ficaram para as últimas colheitas $\left(2 .^{a}\right.$ e $3 .^{a}$ até 1944 , 1." para 1945 em diante), sejam os que são produzidos nos ramos inferiores não eliminados.

Quadro 4.-Maturação do café. Quantidade de café maduro obtida nas colheitas, c percentagem da produção da primeira colheita em relação à produção total anual no período $1935-50$

\begin{tabular}{|c|c|c|c|c|c|c|c|c|c|c|}
\hline \multirow[b]{2}{*}{ Anos } & \multicolumn{5}{|c|}{ Série desbustada } & \multicolumn{5}{|c|}{ Série não desbastada } \\
\hline & $\begin{array}{l}\text { Primei- } \\
\text { ra co- } \\
\text { lheita }\end{array}$ & $\begin{array}{c}\text { Segun- } \\
\text { da co- } \\
\text { lheita }\end{array}$ & $\begin{array}{l}\text { Terceira } \\
\text { colheita }\end{array}$ & $\begin{array}{l}\text { Produ- } \\
\text { cano to- } \\
\text { tal }\end{array}$ & $\begin{array}{l}\text { l'roilu- } \\
\text { cãa l.a } \\
\text { colbeita } \\
\text { em rela- } \\
\text { cãa ao } \\
\text { total }\end{array}$ & $\begin{array}{l}\text { Prinei- } \\
\text { ra ro- } \\
\text { lheita }\end{array}$ & $\begin{array}{l}\text { Segun- } \\
\text { da co- } \\
\text { lheita }\end{array}$ & $\begin{array}{c}\text { Terceira } \\
\text { colheita }\end{array}$ & $\begin{array}{l}\text { Produ- } \\
\text { cão to- } \\
\text { tal }\end{array}$ & 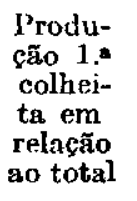 \\
\hline & ОнтіDо & TO $\mathbf{P E 1}$ & o 1935 & 1944 & & & & & & \\
\hline & $\mathrm{kg}$ & $\mathrm{kg}$ & $\mathrm{l}: \mathrm{g}$ & $k g$ & $\%$ & $k g$ & $\mathrm{~kg}$ & $\mathrm{~kg}$ & $k g$ & $\%$ \\
\hline $\begin{array}{l}1935 \ldots \ldots \\
1936 \\
1937 \ldots \\
1938 \\
1939\end{array}$ & $\begin{array}{r}19,17 \\
26,69 \\
48,16 \\
193,44 \\
9,42\end{array}$ & $\begin{array}{r}8,53 \\
43,41 \\
8,43 \\
14,00 \\
3,16\end{array}$ & $\begin{array}{l}2,10 \\
1,40 \\
0,80 \\
1,09\end{array}$ & $\begin{array}{r}27,70 \\
72,20 \\
57,99 \\
208,33 \\
13,67\end{array}$ & $\begin{array}{l}69,2 \\
37,0 \\
83,1 \\
92,9 \\
68,9\end{array}$ & $\begin{array}{r}32,93 \\
29,79 \\
48,66 \\
225,02 \\
14,14\end{array}$ & $\begin{array}{r}14,70 \\
44,67 \\
11,91 \\
24,18 \\
5,28\end{array}$ & $\begin{array}{l}2,40 \\
3,80 \\
1,66 \\
2,37\end{array}$ & $\begin{array}{r}47,63 \\
76,86 \\
64,37 \\
250,86 \\
21,79\end{array}$ & $\begin{array}{l}69,1 \\
38,8 \\
75,6 \\
89,7 \\
64,9\end{array}$ \\
\hline $\begin{array}{l}1940 \ldots \\
1941 \ldots \\
1942 \ldots \\
1943 \ldots \\
1944 \ldots\end{array}$ & $\begin{array}{r}36,50 \\
6,46 \\
24,48 \\
67,48 \\
88,70\end{array}$ & $\begin{array}{r}116,06 \\
2,10 \\
69,74 \\
17,72 \\
46,86\end{array}$ & \begin{tabular}{c|}
36,42 \\
$-6,84$ \\
1,60 \\
3,30
\end{tabular} & $\begin{array}{r}188,98 \\
8,56 \\
101,06 \\
86,80 \\
138,86\end{array}$ & $\begin{array}{l}19,3 \\
75,5 \\
24,2 \\
77,7 \\
63,9\end{array}$ & $\begin{array}{r}41,34 \\
9,24 \\
24,78 \\
75,70 \\
76,40\end{array}$ & $\begin{array}{r}128,30 \\
3,40 \\
78,24 \\
32,66 \\
52,48\end{array}$ & $\begin{array}{r}46,96 \\
12,08 \\
4,02 \\
5,14\end{array}$ & $\begin{array}{r}216,60 \\
12,64 \\
115,10 \\
112,38 \\
134,02\end{array}$ & $\begin{array}{l}19,1 \\
73,1 \\
21,5 \\
68,0 \\
57,0\end{array}$ \\
\hline 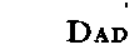 & OBTIDOS & NO PERÍ & ODO 1945 & a 1950 & & & & & & \\
\hline $\begin{array}{l}1945 \ldots \\
1946-\ldots \\
1947-\ldots \\
1948 \\
1949- \\
1950 . \\
\end{array}$ & $\begin{array}{r}65,72 \\
93,02 \\
54,70 \\
75,12 \\
34,96 \\
140,46\end{array}$ & $\begin{array}{r}1,36 \\
6,00 \\
4,08 \\
76,48 \\
10,16 \\
21,80\end{array}$ & $\mid$\begin{tabular}{l}
$-\cdots$ \\
\hdashline$-\cdots$ \\
\hdashline$-\cdots$
\end{tabular} & $\begin{array}{r}67,08 \\
99,02 \\
58,78 \\
151,60 \\
45,12 \\
162,26\end{array}$ & $\begin{array}{l}\mathbf{9 8 , 0} \\
\mathbf{9 3 , 9} \\
\mathbf{9 3 , 1} \\
49,6 \\
77,5 \\
\mathbf{8 6 , 6}\end{array}$ & $\begin{array}{r}97,48 \\
113,10 \\
54,00 \\
80,04 \\
35,28 \\
142,70\end{array}$ & $\begin{array}{r}2,40 \\
11,32 \\
5,70 \\
89,16 \\
9,46 \\
36,16\end{array}$ & 更 & $\begin{array}{r}99,88 \\
124,42 \\
59,70 \\
169,20 \\
44,74 \\
178,86\end{array}$ & $\begin{array}{l}97,6 \\
90,9 \\
90,5 \\
47,3 \\
78,9 \\
79,8\end{array}$ \\
\hline
\end{tabular}




\section{7 - TAMANHO DAS SEMENTES}

Foi continuado o estudo da peneira média para verificar se a eliminação dos ramos inferiores do cafeeîro tem como consequência uma alteração no tamanho das sementes. Na segunda parte do quadro 5, são apresentados os resultados médios obtidos na primeira e segunda colheitas de cada um dos anos do período examinado.

Verifica-se que a série não desbastada produziu maiores sementes na primeira colheita em 1946, 1947, 1949 e 1950 e na segunda, em 1945, 1946, 1947, 1949 e 1950. Apenas ęm 1945 e 1948, a série desbastada deu, na primeira colheita, produto maior que a não desbastada. Com relação à segunda colheita, apenas em 1948 esta série sobrepujou sua competidora.

Apesar de serem geralmente pequenas as diferenças, verifica-se que, no período 1945-50, a série não desbastada em quase todos os anos prođuziu sementes de maior tamanho que a desbastada.

No quadro 5 vem a relação completa das peneiras médias no período de 1935 a 1950 (15 safras).

Quadro 5.-Tamanho das sementes, peneira média do café obtido nas colheitas, nas duas séries, no período 1936-50

\begin{tabular}{|c|c|c|c|c|}
\hline \multirow[b]{2}{*}{ A $\mathbf{n} \circ \mathbf{s}$} & \multicolumn{2}{|c|}{ Série desbastada } & \multicolumn{2}{|c|}{ Série năo deabastada } \\
\hline & $\begin{array}{l}\text { Primeira } \\
\text { colheita }\end{array}$ & $\begin{array}{l}\text { Segunda } \\
\text { colheita }\end{array}$ & $\begin{array}{l}\text { Primeira } \\
\text { colheita }\end{array}$ & $\begin{array}{l}\text { Segunda } \\
\text { colheita }\end{array}$ \\
\hline Dados ontidos No PERfodo 1936 a 1944 & & & & \\
\hline $\begin{array}{l}1936 \\
1937 \\
1938 \\
1939\end{array}$ & $\begin{array}{l}16,95 \\
17,73 \\
17,76 \\
18,37 \\
16,78\end{array}$ & $\begin{array}{l}16,95 \\
17,49 \\
17,45 \\
18,07 \\
17,40\end{array}$ & $\begin{array}{l}16,95 \\
17,83 \\
17,84 \\
18,35 \\
16,90\end{array}$ & $\begin{array}{l}16,90 \\
17,44 \\
17,53 \\
17,80 \\
17,75\end{array}$ \\
\hline 1941 & $\begin{array}{l}16,70 \\
17,47 \\
18,24 \\
16,97\end{array}$ & $\begin{array}{l}17,20 \\
18,06 \\
19,06 \\
17,56\end{array}$ & $\begin{array}{l}16,71 \\
17,37 \\
18,26 \\
17,15\end{array}$ & $\begin{array}{l}17,18 \\
18,36 \\
18,06 \\
17,64\end{array}$ \\
\hline DADOS OBTIDOS NO PERÍODO 1945 a 1950 & & & & \\
\hline $\begin{array}{l}1945 \\
1946 \\
1948 \\
1949\end{array}$ & $\begin{array}{l}17,58 \\
17,44 \\
17,30 \\
17,14 \\
16,99 \\
16,76\end{array}$ & $\begin{array}{l}17,18 \\
17,24 \\
17,58 \\
17,39 \\
16,34 \\
17,12\end{array}$ & $\begin{array}{l}17,56 \\
17,52 \\
17,54 \\
17,03 \\
17,00 \\
16,85\end{array}$ & $\begin{array}{l}17,65 \\
17,43 \\
17,92 \\
17,26 \\
\mathbf{1 6 , 4 4} \\
17,47\end{array}$ \\
\hline
\end{tabular}

Verifica-se que no período todo, em dez safras, a série não desbastada apresentou maiores sementes na primeira colheita $(1937,1938,1940,1941$, $1943,1944,1946,1947,1949$ e 1950 ; e em nove na segunda colheita (1938, $1940,1942,1944,1945,1946,1947,1949$ e 1950). 
Como a primeira colheita em quase todos os anos representou a maior quantidade de café colhido, ficando para a segunda na maioria das vêzes, apenas um repasse, conclui-se que, na maioria das safras, a série não desbastada àpresentou café beneficiado de maior tamanho do que a série desbastada.

\section{8 - CONCLUSÕES}

a) Pelos resultados obtidos verifica-se que houve uma produção maior para as séries não desbastadas no período de 1945 a 1950. No período todo do ensaio, isto é, em dezesseis colheitas (período 1935-1950) a produção tambếm foi maior para os cafeeiros não desbastados. Feito o estudo estatístico dos dados do ensaio (2), verificou-se que o resultado é significativo.

b) Com relação à maturação do café, houve, quase em todos os anos, uma pequena diferença para a série desbastada, que apresentou maiores percentagens de frutos maduros na primeira colheita.

c) Não houve diferença apreciável no tamanho das sementes produzidas pelos dois tratamentos em exame. Em maior número de safras, as sementes da série não desbastada foram um pouco maiores do que as produzidas pela série desbastada.

d) Não existe, pois, vantagem em se fazer a operação da retirada dos ramos inferiores do cafeeiro.

\section{RESUMO}

Foi continuado o ensaio do desbaste dos ramos inferiores do cafeeiro, instalado na Estação Experimental Central de Campinas, em 1932.

$O$ ensaio compreende duas séries : $a$ ) desbastada ; b) não desbastada. Cada série se compõe de 5 repetições com 25 cafeeiros cada uma. A variedade em cultivo foi a Coffea arabica L. var. typica Cramer.

A série desbastada foi mantida sem os ramos primários até uma altura de $50 \mathrm{~cm}$ do solo. Na séric não desbastada não se interferiu de modo algum nessa parte da planta.

As colheitas foram iniciadas em 1935. A série não desbastada produziu significativamente mais, no período todo examinado, isto é, em dezesseis safras (1935-1950).

Não houve grande diferença no tamanho das sementes. A maturação foi um pouco apressada na série desbastada.

$O$ ensaio demonstra que não houve vantagem em se fazer esta operação.

\section{SUMMARY}

The experiment, begun at the Central Experiment Station at Campinas in 1932, on the pruning of the lower branches of coffee plants, has been continued. 
The trial contains two series, $a$ ) pruned and $b$ ) not pruned. Each series consists of five replicates, each with 25 coffee plants. The variety is Coffea arabica $\mathbf{L}$. var. typica Cramer.

The pruned trees were kept free from primary branches to a height of $50 \mathrm{~cm}$. The unpruned trees were left entirely untouched in this region.

Harvesting began in 1935. The unpruned trees have yielded significantly better $(P=5 \%)$ over the period of the 16 years of the trial (1935-1950).

There was no great difference in size of seeds. Ripening was advanced a little in the pruned trees.

The experiment showed that there was no advantage to bo gained by pruning ; on the contrary, the operation appears to be prejudicial to the yield.

\section{LITERATURA CITADA}

1. Mendes, J. E. Teixeira. Ensaio de desbaste de ramos inferiores do cafeeiro. I. Bragantia 6: 567-582. 1946.

2. Stevens, W. L. e C. G. Fraga Jr. Análise do ensaio de desbaste dos ramos inferiores do cafeeiro. Bragantia 11: 285-289. 1951. 